\title{
Impact of diffuse solar radiation on HAM simulation accuracy
}

\author{
Peter Juras ${ }^{1, *}$ \\ ${ }^{1}$ Department of Building Engineering and Urban Planning, Faculty of Civil Engineering, University \\ of Zilina, Univerzitna 8215/1, 01026 Zilina, Slovakia
}

\begin{abstract}
Advance in the numerical simulation models brings higher need for more accuracy outdoor boundary conditions - climate data sets. With influence of the urban heat islands, measured climate on the meadows, far from pawed surfaces creates uncertainty in the simulation. Another problem is the modelling of solar radiation impact on the surface temperatures. Solar radiation heats up the surface of the structure and increase the speed of vapor transport. To obtain correct results, global and diffuse solar radiation is needed in the HAM software. In this paper, influence of the diffuse part of solar radiation is analyzed. As it would be shown, correct modeling of the solar radiation, both global and diffuse is very important to reach good precision. This analysis is done in software WUFI Pro and compared with the experimental measurement of the wooden wall fragments.
\end{abstract}

\section{Introduction}

Accuracy of Heat-Air-Moisture (HAM) simulation depends on detailed material properties $[1,2]$ as well as on boundary conditions. Aim of this article is the solar radiation. As sunlight passes through the atmosphere, some of it is absorbed, scattered, and reflected by: air molecules, water vapor, clouds, dust, pollutants etc. This is called diffuse solar radiation. The solar radiation (SR) that reaches the Earth's surface without being diffused is called direct beam solar radiation. The sum of the diffuse and direct solar radiation is called global solar radiation. Atmospheric conditions can reduce direct beam radiation by $10 \%$ on clear, dry days and by $100 \%$ during thick, cloudy days.

The global solar radiation is widely measured by the automated weather stations belonging to the Slovak Hydrometeorological Institute (SHMI), national weather service [3]. But the diffuse solar radiation is measured only in six locations thorough the country. This creates difficulties by use of measured datasets, because of lack of diffuse component. There have been many efforts in the past to develop algorithms for the derivation of the diffuse fraction of global solar radiation. Several methods are compared in [4, 5]. Analysis of the models is not only limited to the short-wave radiation, but also to the long-wave one, which is important for calculation of the heat flow and surface temperatures influenced by the sky radiation $[6,7]$. In this paper, measured global and diffuse radiations are analyzed

\footnotetext{
* Corresponding author: peter.juras@fstav.uniza.sk
} 
and used as boundary conditions in HAM software and simulation results are compared to the experimental wooden wall measurement.

\section{Outdoor climate measurement}

Department of Building Engineering and Urban Planning has its own experimental weather station (WS). The outdoor climate has been recorded since 2013. The comparison to the datasets from the nearest weather station belonging to the SHMI network and campus ' weather station can be found in previous articles [8,9]. Since 2017, the newer WS, measuring more meteorological quantities (including diffuse solar radiation), is in use. For purpose of this paper also the data from a façade meteorological station (FAMS) were used [10]. This FAMS records the short and long wave solar radiation on the vertical surface with same southern orientation as the experimental wooden wall [11] used for the comparison of temperatures from the simulation. Devices used for measurement of solar radiation are shown in Fig. 1.
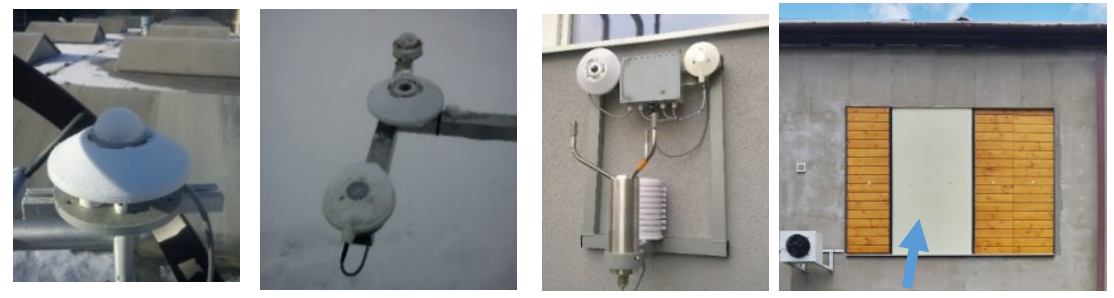

Fig. 1. Set of devices for monitoring of the solar radiation. Figures are taken during the daily winter maintenance, from left: weather station' shaded pyranometer for diffuse radiation, pyrgeometer, pyranometer and UV radiation meter and FAMS, right - view at used experimental wooden wall.

In this paper, measured outdoor climate from the WS was used. Data of solar radiation (long and short wave) were used also from the FAMS. Dealing with accurate Heat-AirMoisture (HAM) simulation, global SR and its diffuse component are very important.

Diffuse solar radiation component is measured by shaded pyranometer (Fig. 1). The shading ring displacement is operated manually. The sensor on the shading ring is able to measure the diffuse incoming solar radiation from the upper hemisphere (solid angle of $2 \pi$ - the obscured fraction of the ring). To obtain an estimation of the incoming radiation that would be received from the entire hemisphere and compensate for the obscured fraction of the shading ring, a correction can be applied. The factor for uniform sky radiation can be calculated using an equation stated in [12]. This factor is changing regularly every day with the highest value during summer. Comparison with corrected values and measured diffuse radiation for one summer and winter day is presented in Fig. 2.
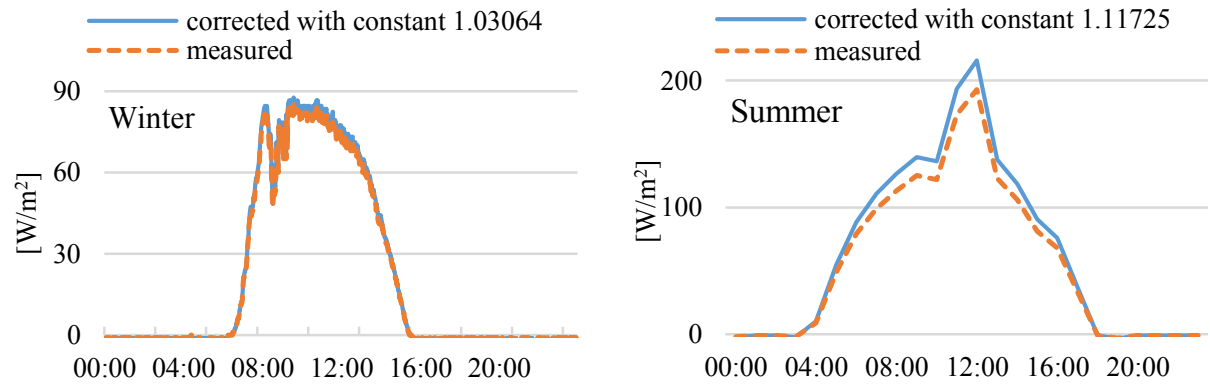

Fig. 2. Comparison of measured diffuse radiation courses and the corrected ones [12]. 


\section{Heat-Air-Moisture simulation}

Software used in this paper is WUFI Pro in version 6.2 [13]. WUFI is a software which allows a realistic calculation of the transient coupled one dimensional heat and moisture transport in multi-layer building components exposed to the real climate conditions. Data measured by the WS $[9,10]$ enter the software as outdoor boundary conditions. Material properties of the wall tested in simulation were taken from the software library.

Simulated wall composition was taken from the wooden wall research [11] and it is described in Table 1. It is a southward oriented wall with coating on the outdoor surface.

Table 1 Detailed structure of the reference wall (from outside) [11].

\begin{tabular}{|c|c|c|c|c|}
\hline $\begin{array}{c}\text { Wooden-framed } \\
\text { wall }\end{array}$ & $\begin{array}{c}\text { External acrylic } \\
\text { coating }\end{array}$ & $\begin{array}{c}\text { Woodfiber } \\
\text { MDF Board }\end{array}$ & $\begin{array}{c}\text { Mineral wool } \\
\text { insulation }\end{array}$ & $\begin{array}{c}\text { Vapor barrier } \\
\text { OSB Board }\end{array}$ \\
\hline Thickness $[\mathrm{mm}]$ & 4 & 100 & 220 & 12 \\
\hline
\end{tabular}

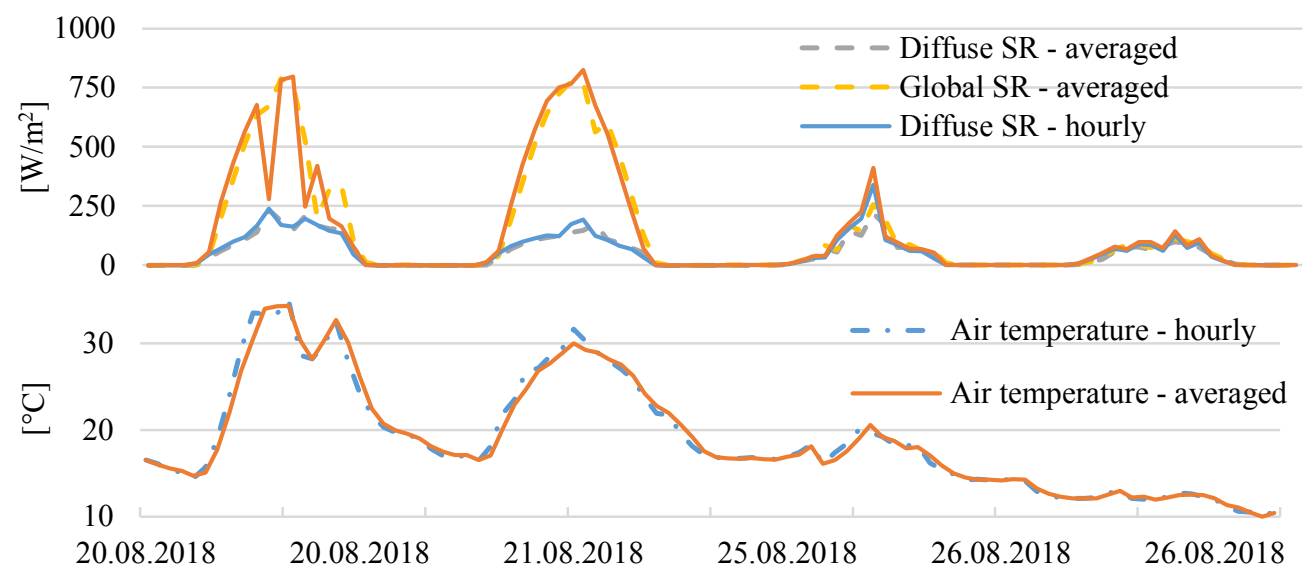

Fig. 3. Selected summer days as an input for the simulation, sunny 20. and 21.8., cloudy 25 . and 26.8 .

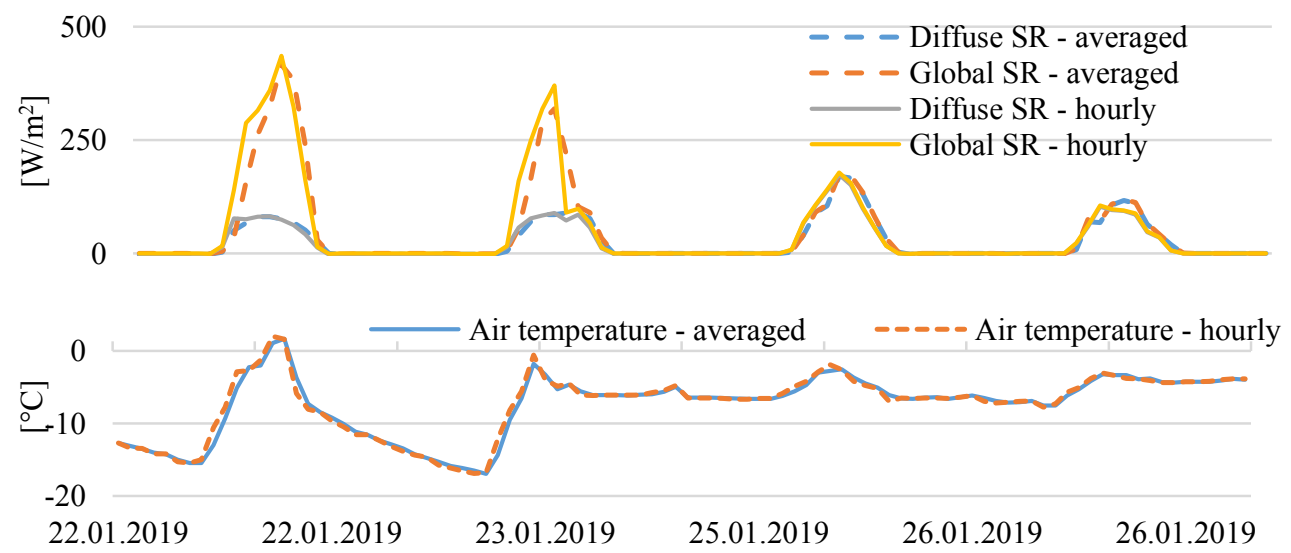

Fig. 4. Selected winter days as input for the simulation, sunny 22. and 23.1., cloudy 25. and 26.1.

For purpose of this paper two four-days periods were selected, both combined with sunny and cloudy days, to investigate the impact of diffuse radiation. Summer days - sunny 20. and 21.8, cloudy 25. and 26.8. Winter days, sunny 22. and 23.1., cloudy 25. and 26.1. Hourly courses of solar radiation and air temperatures are shown in Fig. 3 and 4. The values are interpreted as hourly values without averaging and also as hourly average from one- 
minute values. The differences are neither significant in boundary conditions courses nor in simulated courses. More different settings in WUFI were used, such as advanced radiation balance (Fig. 5) with both - short and long wave radiation and counter radiation. All variants are summarized in Table 2.

Table 2 Different boundary conditions and WUFI settings.

\begin{tabular}{|c|c|c|c|}
\hline $\begin{array}{l}\text { Global solar radiation } \\
\text { (short wave) }\end{array}$ & $\begin{array}{l}\text { Long wave } \\
\text { radiation }\end{array}$ & Radiation, radiation balance & $\begin{array}{c}\text { Short-wave radiation } \\
\text { absorptivity factor }\end{array}$ \\
\hline \multicolumn{2}{|c|}{$\begin{array}{l}\text { measured on horizontal surface } \\
\text { (orientation and inclination for the wall } \\
\text { calculated by WUFI) }\end{array}$} & $\begin{array}{l}\text { explicit radiation balance (ERB) } \\
\text { (radiative cooling taken into } \\
\text { account) }\end{array}$ & 0.3 \\
\hline \multirow{2}{*}{\multicolumn{2}{|c|}{$\begin{array}{c}\text { measured on vertical surface (FAMS), } \\
\text { southward orientation }\end{array}$}} & short wave and long wave & 0.55 \\
\hline & & wind-dependent heat resistance & \\
\hline
\end{tabular}

atmospheric counterradiation

diffuse solar radiation
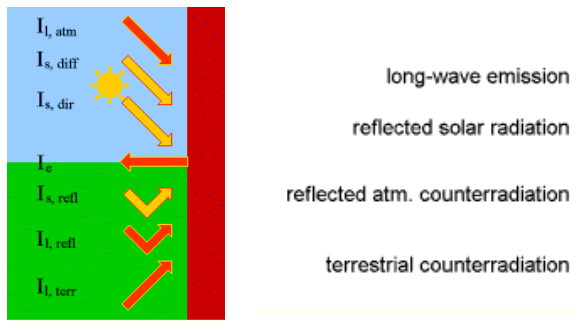

direct solar radiation

reflected atm. counterradiation

terrestrial counterradiation

Fig. 5. Solar radiation components, which influence the simulated structure in WUFI software when explicit radiation balance (ERB) is enabled (source WUFI software help)

\section{Results and discussion}

Results in term of comparison of daily temperature courses (results from the simulation and the measured ones) are shown in Fig. 6 for summer days and in Fig. 7 for winter days. Summer period shows a very good match with use of short wave absorption (SWA) set to 0.3 , which represents a bright surface. This value was neither measured, nor stated by the manufacturer of the coatings. It was obtained by the different calculation attempts and the best match was obtained with it. If the simulation uses the measured global radiation on vertical surface (from FAMS) with diffuse radiation (WS) the results are almost the same. If there is no diffuse SR component incorporated (combined with FAMS), SWA needs to be higher, good match was obtained by use of the value 0.55 .

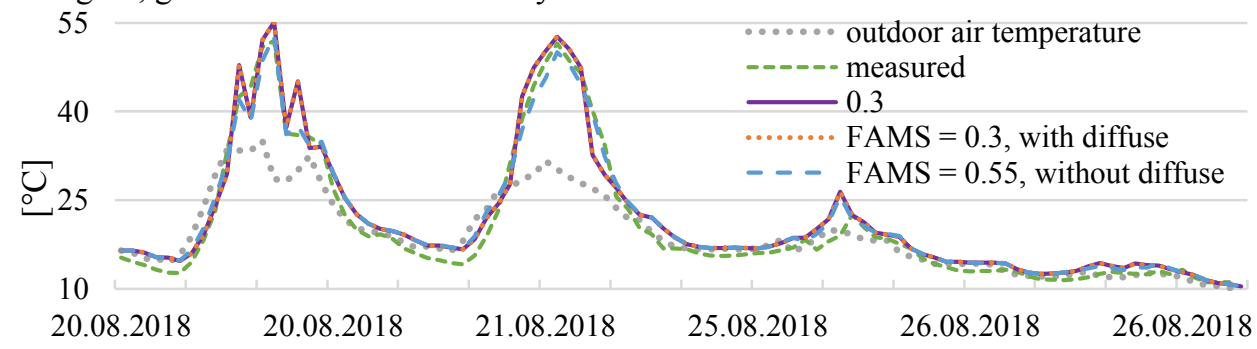

Fig. 6. Simulation results represented as daily temperature courses for summer period and different absorption and boundary conditions

If there is no diffuse component and only global SR is measured by WS, simulated surface temperatures are identical to the outdoor air temperature, in that case WUFI cannot 
calculate the temperatures correctly. Results showed, that summer days do not need advanced WUFI settings, only correct SWA has to be set up.

Results for winter period (Fig. 7) show big difference during the night between air temperature measured by the WS and outdoor surface of the wall. This difference is caused by the sky radiation during the cloudless night (enabling of ERB helps during the night from days 22 to 23). On the contrary, during the other days/nights, these settings disturb the match of courses. At the bottom part of the Fig. 7, courses based on modified outdoor temperature: combination of air temperature during the day and derived from the measured surface temperature during the night are shown. With this combination, the match is better except first morning.

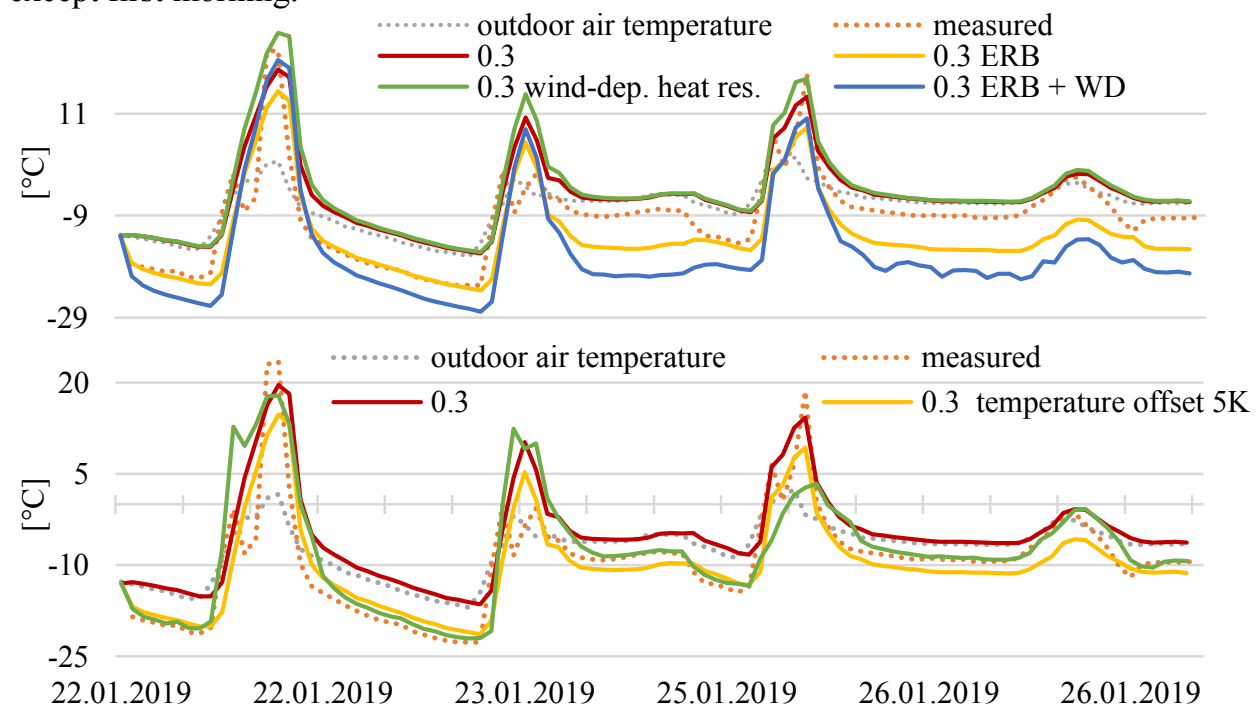

Fig. 7. Simulation results represented as daily temperature courses for winter period and different absorption and boundary conditions. Bottom figure represents simulation with modified outdoor temperatures

Closer look is presented in Fig. 8. The measured course is changing up and down, but in the simulated one, the temperature is still increasing. This difference is caused by the use of hourly averages of global solar radiation, which does not represent the real boundary conditions good enough. Rapidly changing global SR is not sufficiently represented by the hourly averages, which creates the differences between measured and simulated surface temperatures. These courses showed the direct dependence of global SR (together with use of diffuse component) and surface temperature.

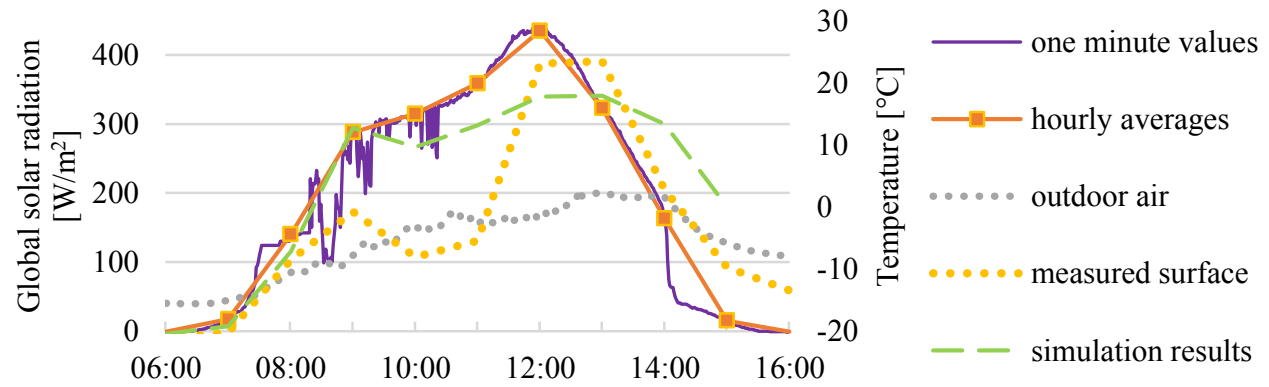

Fig. 8. Detailed courses of measured global solar radiation and surface temperatures of used experimental wall (measured and simulated with SWA 0.3 ) on 22.01 . 


\section{Conclusion}

In this paper, influence of the global and diffuse solar radiation incorporation within boundary conditions was analyzed. More possibilities in the WUFI software were used to obtain the best results in comparison to the real measured surface temperatures on the experimental wall. A pretty good match was found during summer, but only with using also diffuse radiation component. Without it, the software cannot calculate the surface temperatures correctly.

Winter comparison showed a problem with temperature differences during the cloudless night. Another difference is caused by the rapid change of SR (passing clouds), where the hourly averages cannot describe the outdoor climate good enough. Basic averaging of the one minute values did not work well. This creates the possibility for further research and trying to use better calculation model of hourly values. Best SWA for this wall composition (bright coating) were obtained, which will be confirmed with identical wall oriented towards the east. Measurement with spectrophotometry will be conducted to obtain the short wave absorbance and compare with the one based on the best simulation match.

The research was done with the support of a grant project VEGA no. 1/0945/16.

\section{References}

1. M. Vertal, P. Durica, Bestimmung von feuchtetechnischen Material - parametern ausgewählter Baumaterialien für die rechnerische Bewertung von Baukonstruktionen unter den Bedingungen in der Slowakei, J. Bauphysik, vol. 31, pp. 386-392 (2009)

2. M. Vertal et al., Hygrothermal initial condition for simulation process of green building construction, J. Energy and Building, vol. 167, pp. 166-176 (2018)

3. Slovak Hydrometeorological Institute, site: www.shmu.sk

4. A. Mahdavi, S. Dervishi, Approaches to computing irradiance on building surfaces, $J$. of Building Performance Simulation, pp.129-134, (2010)

5. S. Dervishi, A. Mahdavi, Computing diffuse fraction of global horizontal solar radiation: A model comparison, J Solar Energy, vol. 86, pp. 1796-1802 (2012)

6. M. Cekon, Accuracy analysis of longwave sky radiation models in the MZELWE module of the ESP-r program, J. EnBuild, vol. 103, pp. 147-158 (2015)

7. R. Slavik, M. Cekon, Monitoring the Effective Ambient and Sky Temperature Based on Infrared Sensor for Advanced Thermal Calculations, J. Applied Mechanics and Materials, vol. 887, pp. 613-621 (2019)

8. D. Staffenova et al., Climate Data Processing for Needs of Energy Analysis. J. Advanced Materials Research: enviBUILD, vol. 1041 pp. 129-134 (2014)

9. D. Jurasova, Analysis of long-term measured exterior air temperature in Zilina, J. CEE vol. 14 pp.124-131 (2018)

10. P. Juras et al., Full scale climate measurement around the building façade, Advanced Building Skins, Bern (2017)

11. D. Staffenova et al., Evaluative Case Study in Lightweight Wooden Wall Research, J. Applied Mechanics and Materials, vol. 887, pp. 56-63 (2019)

12. A. Oliveira et al., A New Shadow Ring Device for Measuring Diffuse Solar Radiation at the Surface, J. of Atmospheric and Oceanic Technology, vol. 5, pp. 698-708 (2002)

13. WUFI Pro 6.2, Fraunhofer Institute for Building Physics, site: www.wufi.de 